\title{
Knowledge, Attitude and Practice on Malaria and Associated Factors Among Residents in Pawe District, North West Ethiopia: A Cross-Sectional Study
}

\author{
Habtamu Bedimo Beyene ${ }^{1,}$, , Nigus Fikrie Telele ${ }^{2}$, Asrat Hailu Mekuria ${ }^{2}$ \\ ${ }^{1}$ Department of Medical Laboratory Sciences, College of Health Sciences, Wollega University,Nekemte, Ethiopia \\ ${ }^{2}$ Department of Microbiology, Immunology and Parasitology,College of Health Sciences, Addis Ababa University, Addis Ababa, Ethiopia
}

Email address:

habtish1976@gmail.com (H. B.Beyene), fikrienigus2000@gmail.com (N.F. Telele), hailu_a2004@yahoo.com (A. H. Mekuria)

\section{To cite this article:}

Habtamu Bedimo Beyene, Nigus Fikrie Telele,Asrat Hailu Mekuria. Knowledge, Attitude and Practice on Malaria and Associated Factors Among Residents in Pawe District, North West Ethiopia: A Cross-Sectional Study. Science Journal of Public Health.

Vol. 3, No. 3, 2015, pp. 303-309. doi: 10.11648/j.sjph.20150303.11

\begin{abstract}
Introduction:A high knowledge score about the cause, transmission and habit of practicing the availablepreventive and control measures by the individual households and the communityat large contribute much to the overall reduction of the malaria burden. Hence this study is aimed to asses the Knowledge, attitude and practice towards malaria and associated factors. Methods:A community-based, cross sectional study was carried out in the period November, 2010 to January, 2011 in Pawi district, North West Ethiopia. A multi-stage random sampling technique was carried out to select representative households. A pre-tested structured questionnaire was used for data collection. Data was entered and analyzed using SPSS 16.0. Proportions, Oddsratio and $95 \%$ CI were computed. Results: A total of 406 subjects were included in this study. Two hundred eighty (67\%) of them were females. Subjects who mentioned at least three symptoms of malaria constituted $71.5 \%$. Fifty six percent associated malaria with skipping meals, as a cause and most (67\%) affirmed that mosquitoes transmit the disease. Significant proportions (79.8\%) were aware that mosquitoes bite during night. Sleeping under bed net and avoiding collected water sources were identified as major malaria preventive measures by $89.7 \%$ and $34 \%$ of subjects respectively. About $69.2 \%$ reported that they were using bed nets correctly. Over $50 \%$ of therespondents stated that they would not seek treatment within 24 hours of onset of symptoms. Participants who had education $>5$ th grade and those who received health education from a health facility scored high on knowledge about malaria, correct use of bed nets and early treatment seekinghabits [OR $(95 \% \mathrm{CI})$ $=4.9(1.4-8), 1.8(1.4-2.5), 2.2(1.7-4.1)$, respectively]. Living in locations away from a health facility with walking time of 60 minutes or longerwas associated with delay in treatment $(\mathrm{OR}=1.3,95 \% \mathrm{CI}=$ (1.1-2.0).Conclusions and recommendations:Though malaria knowledge and Attitude scores were high,the practice of nationally approved malaria preventive and control measures including early treatment seeking behavior were poor. Inaccessibility of health facility, illiteracy, and lack of health education were determinant factors that affected community KAP towards malaria. Hence, a comprehensive health education, promotion of community education and health facility coverage should be prioritized.Responsible bodies are also urged to ensure that all individual in a household use ITNscorrectly, adapt integrated vector control approach and seek treatment early.
\end{abstract}

Keywords: Malaria, Determinants, KAP, Pawe, Northwest Ethiopia

\section{Introduction}

Malaria is one of the major causes of morbidity and mortality among peopleliving in tropical and subtropicalregions [1].Humans are infected through a bite of an infected femaleAnophelesmosquito that inoculates spindle shaped sporozoites into the bloodstream[2]. There are four malaria species that infect and cause disease in humans, Plasmodium falciparum, $P$. vivax, $P$. malariae and $P$. ovale.Approximately $75 \%$ of the landmass in Ethiopia is malarious with about $68 \%$ of the totalpopulationliving in areas at risk of malaria. Malaria casesthat had occurred in Ethiopia ataltitudes of $>2000$ meters above sea level are almost exclusively due toPlasmodium vivax unlike in the lowlands $(<1500$ meters above sea level)where P. falciparum is the dominant parasite species.According to Ethiopia's 
Federal Ministry of Health (FMOH) report in2008/2009, malaria was the first cause of outpatient visits, health facility admissions andin-patient deaths, accounting for $12 \%$ of outpatient visits and $9.9 \%$ of admissions.However, as $36 \%$ of thepopulation does not have access to health care services, thesefigures probably under-represent the true burden of malaria in the country [3]. The mortality due to malaria is reported to be 70,000 deaths each year.The socioeconomic burden resulting from malaria is immense, to mention a few: (1) it significantly reducesproduction activities (2) the prevalence of malaria in many resource-rich regionsof the countryprevents the movement and settlement of people in resource-rich low-lying river valleys (3)the increased school absenteeism during malaria epidemicssignificantly reduces learningcapacity of students (4) imposes undue increases in public health expenditures [4].On the other handover the last decade, the morbidity, hospital admissions and fatality rates related tomalaria have beenreduced significantly. Theannual inpatient admissions of malaria cases, malaria deaths, and malaria epidemics in Ethiopia have substantially decreased through 2012, compared to the baseline year of 2004 [5].Community perceptions relating to causation, diagnosis, treatment and prevention are the main socio-cultural factors which can influence malaria prevention and control [6].Factors such as the household socio-economic status, parents' education, the householdhead's sex and age, distance of homesteads to health facility, and the quality of health care serviceshave all been found to influence people's treatment and provider choices [7]. Only a few studies have been conducted in Ethiopia regardingcommunity knowledge aboutmalaria and how to combat it [7,8].Moreover, despite high endemicity of malaria in Pawe district, no data exists regarding the awareness of local community and determinants of KAP towards malaria.The understanding of the possible causes, modes oftransmission, and individuals' preference and decision about adoption of preventive andcontrol measures vary from community to community andeven among individual households[9]. Moreover, KAP studies unequivocally would therefore provide information necessary to support and guide the malaria control approaches and policies regionally and locally. The main aim of this study was therefore, to asses some of the determinants of knowledge, attitude and practice (KAP) of the local community about malaria transmission and its control measures in Pawe District, North Western part of Ethiopia.

\section{Materials and Methods}

\subsection{Study Area}

Thestudy was conducted among residentsof a rural community in Pawe districtwhich is located 565 kilometresto the North West ofAddis Ababa, capital of Ethiopia. The total population of the district was about 42,443 of which 21,588 were males and 20,855 females, yieldinga male to female ratio of approximately $1: 1$ at the time of data collection. The district had a total of 20 villages from which 3 were urban and the rest 17 were ruralwith an estimated 10,610 households. Each village had an average family size of 4 persons per household.

\subsection{Study Design}

Across-sectional community based study design was employed among permanent residents of Pawe district to study the Knowledge, attitude and practice (KAP) of control measures and associated factors in 2012.

\subsection{Study Population}

The study subjectsincluderandomly selected household heads living in the selected villages. They were permanent residentsin the village.

Inclusion criteria: adults ( $>18$ years old) who qualify for interview and were volunteers.

Exclusion criteria: Some members of the community members were excluded from the study,either because they were unable to communicateorcouldn't fulfill the inclusion criteria.

\subsection{Sample Size and Sampling Technique}

Sample size wasdetermined using single population proportion estimate fordescriptivestudy considering the level of significance at 0.05 and with an estimated $50 \%$ of population would have an understanding of malaria, as there were no studies done in this area. Stat cal of Epiinfo7 was used for this purpose. Hence using the formula $\left(n=Z^{2} p(1-\right.$ $\mathrm{p}) / \mathrm{d}^{2}$, where $\mathrm{n}=$ sample size, $\mathrm{z}=\mathrm{z}$ statistic for a level of confidence $(\mathrm{z}=1.96$ at $95 \% \mathrm{CI}), \mathrm{p}=$ expected proportion of population $(\mathrm{p}=0.5), \mathrm{d}=$ precision (if $5 \%, \mathrm{~d}=0.05)$. Hence considering $10 \%$ non response rate, the final sample size was calculated as $n=406$.

A multistage sampling technique was used to select the representativehouseholds. Accordingly, threevillages were randomly selected from the list of 20 villages. Secondly, for each of the selected villages, a list of all clusters was made with the assistance ofvillage/sub-village heads from which two clusters were randomlyselected from each kebele.Then, a total of six clusters were drawn from three villages.Finally, the list of all households were made for each cluster from which households wererandomly drawn proportionally to bring a total sample size of $n=406$.

\subsection{Data Collection Technique}

Questionarie: a standard KAP questionnaire adapted from reviews from previous studies was used. The data collection tool consisted of(1)sociodemographiccharacterstics(2)knowledge, attitude and practice (KAP) related questions and (3)Factors associated with KAP.The questionnaire was first prepared in English,then translated into the national language (Amharic)and then translated back to English to checkconsistency and phrasing of difficult concepts. Three data collectors and two supervisors were involved. Face to face interview was employed to obtain information from 
participants. In cases when a respondent was not found, at home during the first visit, one more visit was undertaken.

Variables: The independent variables include socio demographic characteristics (age, sex, marital status, residence, educational status, source of income,health education, accessand utilizationof mass media, housing condition of the community members, and distance of homesteads from health facilities.

Data Quality Assurance: Data collectors and their supervisor weretrained for all aspects of data collection.Before actual data collection was commenced pretest was conducted involving 21 households $(5 \%$ of the sample size) which were not included in the main study. Any incomplete and ineligible questionnaireswere correctedaccordingly. The supervisor and principal investigator closely supervisedthe performance of the data collectors on a daily basis andthe collected record sheets were thoroughly scrutinized every.

Data analysis: Data was entered and cleaned through EPI Info Version 3.5.1 and analysis was done by SPSS V. 20. Bivariate analysis was carried out to determine the association among various variables. A multiple logistic regression analysiswas carried out. P-Value of less than 0.05 was used as a cut off point for declaring the presence of statistically significant association. Odds ratios and 95\% confidence intervals were also computed.

\section{Measurement of Knowledge and Attitude}

A series of questions were used to assessKAP level of participants. Scores were generated for eachquestions related to knowledge, attitude and practice. One mark was awarded for every correct answer. Based on the number of correct answers, the average scores percent was generated for the attitude, knowledge and attitude. A total score of less than $50 \%$ was rated as poor, and over than this as high. To seek treatment not later than 24 hours of the onset of symptoms was defined as an 'early treatment seeking behavior'. 'Correct utilization of bed nets' if in the house hold all family members use nets all year round.

Ethical clearance:Ethical approval was obtained from Research and Ethics Committee (REC) of the Department of Microbiology, Immunology and Parasitology and Institutional Review Board (IRB) of the College of Health Sciences, Addis Ababa University.Averbal informed consent was obtained from each respondent. All respondents were informed about the objectives,procedures and benefits of the study in detail.The consenting procedure ensured that participants were giving consent voluntarily by explaining that refusal/withdrawal from participation would not bring any adverse consequences in terms of accessing any servicesthey are entitled toas other members of community.

\section{Results}

\subsection{Socio Demographic Characteristics of Study Subjects}

A total of406 subjects were included in this study. Two hundred eighty $(67 \%)$ of them were females. The mean (SD) age of participants was 40.6(13). More than half of the respondents $(67 \%)$ had no formal educationand were unable to read and write. Above $75 \%$ of the subjects were married at the time of data collection. Regarding housing condition $55.5 \%$ and $29 \%$ of the house wall was made up of mud and bare wood respectively, though $58.4 \%$ of the roof is made up of corrugated iron sheet. About $66 \%$ of the households had no access to mass media like radio, television and/ or magazines(Table 1)

Table 1. Sociodemographic characteristics of the respondents PaweDistrict, Ethiopia,November, 2010 - Januuary, 2011.

\begin{tabular}{|c|c|}
\hline Variables & $\mathbf{N}(\%)$ \\
\hline \multicolumn{2}{|l|}{ Sex } \\
\hline Male & $126(31)$ \\
\hline Female & $280(69)$ \\
\hline \multicolumn{2}{|l|}{ Age } \\
\hline $18-24$ & $26(6.7)$ \\
\hline $25-34$ & $139(35.6)$ \\
\hline $35-44$ & $78(20)$ \\
\hline $45-54$ & $82(21)$ \\
\hline$>55$ & $65(16.6)$ \\
\hline Mean age $+\mathrm{SD}$ & $40.6+13$ \\
\hline \multicolumn{2}{|l|}{ Residence } \\
\hline Rural & $142(35)$ \\
\hline Urban & $264(65)$ \\
\hline \multicolumn{2}{|l|}{ Educational status } \\
\hline No formla education & $281(67)$ \\
\hline $1-4^{\text {th }}$ grade & $71(16)$ \\
\hline $5-8^{\text {th }}$ grade & $45(11)$ \\
\hline $9-12^{\text {th }}$ grade & $17(4)$ \\
\hline College/University level & $5(2)$ \\
\hline \multicolumn{2}{|l|}{ Religion } \\
\hline Orthodox christian & $182(45)$ \\
\hline Muslim & $142(35)$ \\
\hline Others & $82(20)$ \\
\hline \multicolumn{2}{|l|}{ Family size } \\
\hline $1-4$ & $230(56.6)$ \\
\hline $5-8$ & $153(37.7)$ \\
\hline$>8$ & $23(5.6)$ \\
\hline \multicolumn{2}{|l|}{ Access to media } \\
\hline Yes & $138(34)$ \\
\hline No & $268(66)$ \\
\hline
\end{tabular}

\subsection{Knowledgeand Attitude Towards Malaria.}

Out of 406 participants, 402(98.5\%) had stated at least one of the signs and symptoms ofmalaria and about $71.5 \%$ stated at least three symptoms. A substantial number ofrespondents hadreasonable knowledge about malaria, including correct associationbetween malaria and mosquito bites, its potential impacts andtreatment options. As shown in (Figure 1) below, about $344(84.7 \%)$ and $341(83 \%)$ of the respondents stated fever and headache respectivelyas the most common primary symptoms associated with malaria.

Hunger, fatigue and mosquitoes were mentionedby 228 $(56.7 \%), 180(44.6 \%)$ and $184(45.3 \%)$ of the respondents as causes of malaria respectively (Figure 2)

Malaria was perceived as serious diseases that lead to 
hostile consequence by $89 \%$ of subjects. Similarly, $58 \%$ believed that malaria could cause death unless proper treatment is sought. Moreover, 156(38\%) stated loss of family income as a negative impact of the disease and $97 \%$ believed that malaria is preventable. The overall knowledge score was rated asover 50\% /high.

\section{- frequency percentage}

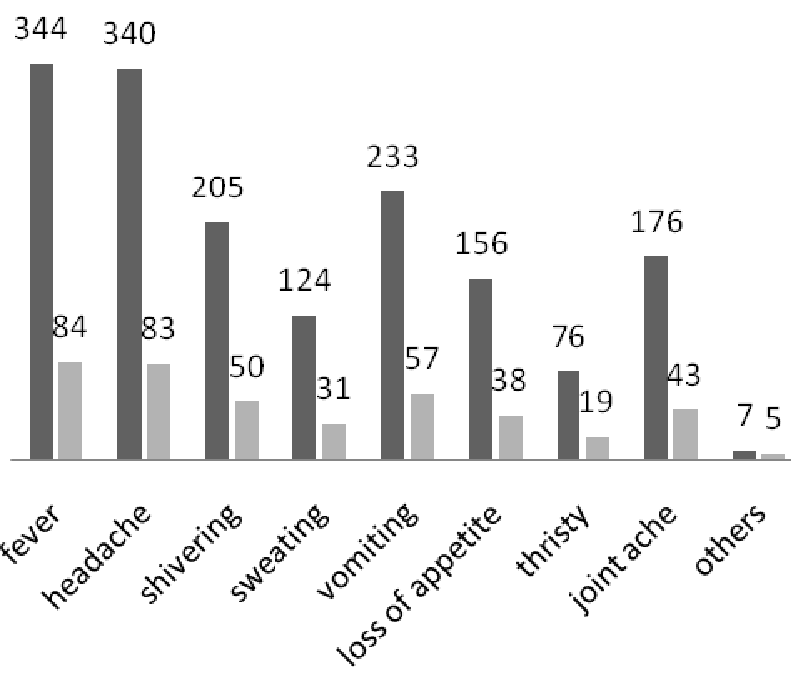

Fig1. Malaria symptoms reported by subjects, Pawe District, Ethiopia, November, 2010 - Januuary, 2011.

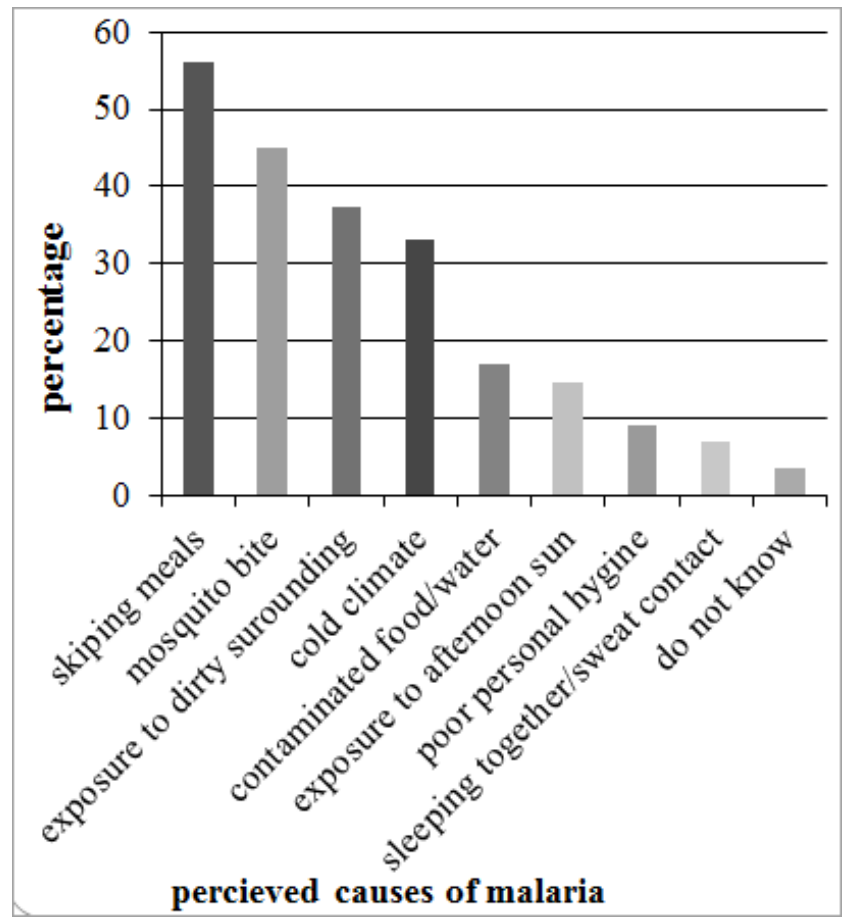

Fig 2. Perceived causes of malaria, Paw District, January 2011

\subsection{Malaria Prevention and Control Measures}

Over $97 \%$ of the study subjects believed that malaria can be prevented and almost all(99\%) stated that malaria is a curable disease. Sleeping under bed net and avoiding collected water sourceswere mentioned by $89.7 \%$ and $33.7 \%$ of subjects respectively as preventive measures of malaria (Table 2).

Table 2. Malaria preventive measures reported by the respondents, Pawedistrict,BenishangulGumuz Regional State, November, 2010 Januuary, 2011.

\begin{tabular}{lll}
\hline Preventive measure & Frequency & Percent \\
\hline Use of bed net & 364 & 89.7 \\
Chemical spray & 82 & 20 \\
Drainage of stagnant water & 222 & 34 \\
Personal hygiene & 45 & 11 \\
Smoking certain type of leaf & 56 & 14 \\
Appropriate nutrition & 17 & 4 \\
No action & 45 & 11 \\
\hline
\end{tabular}

A $92 \%(n=373)$ of the respondents reportedthat all family members usedITNsand $<10 \%$ mentioned that only children under the age of five and women use ITNs. It was $70 \%$ of therespondents that mentioned correct use of ITNs both in terms of season (throughout the yearand following the rainy season) (Table 3).

Table 3. Pattern of bed net use, in PaweDistrict, Pawe-Ethiopia, November, 2010 -Januuary, 2011.

\begin{tabular}{lll}
\hline Family member who use bed net & Frequency & percent \\
\hline All & 373 & 92 \\
Children & 19 & 5 \\
Women & 6 & 1.5 \\
Pregnant & 2 & 0.5 \\
Time of using bed net & & \\
Consistent(every day) & 255 & 70 \\
Inconsistent & 107 & 30 \\
Consistent use of bed net & & \\
Rainy season & 19 & 5 \\
Following rainy season & 117 & 32 \\
$\begin{array}{l}\text { Throughout the year } \\
\text { Correct use of bed net(all year roung with }\end{array}$ & 228 & 63 \\
all family members) & 281 & 69 \\
\hline
\end{tabular}

Most subjects (71\%) perceived early diagnosis and prompt treatment at health facility to cure malaria. A similar proportion of subjects stated that good nutrition asimportant as medical therapy to prevent and cure malaria. Early treatment seeking habit for malaria was reported by only $234(57.6 \%)$ subjects. Delays were mentioned by $42.4 \%$ of respondents.

\subsection{Factors Associated with Knowledge, Attitude and Practice}

The results of multivariate analyses showed that: persons who were $9^{\text {th }}$ grade or abovewere 4.9 timesmore likely to report a high score of malaria knowledge compared to those who had no formaleducation. Respondents from urban setting frequently reported high knowledge score $[\mathrm{OR}=1.5,95 \% \mathrm{CI}=$ $(1.2,4.5)]$. Participants who had constant monthly income reported higher knowledge scores $[\mathrm{OR}=1.8,95 \% \mathrm{CI}=(1.08$, 3.8)]. To not have attended health education regarding malaria was significantly associated with low score of malaria knowledge $\quad[\mathrm{OR}=2.2, \quad 95 \% \mathrm{CI}=\quad(1.9-3.2)]$. Inaccessibility of mass media (such as radio, television or 
both) wassignificantly associated with low score of malaria knowledge $[\mathrm{OR}=1.7,95 \% \mathrm{CI}=(1.3,4.2)$.

Participants' age was significantly associated with correct utilization of ITNs $[\mathrm{OR}=1.295 \% \mathrm{CI}=(0.3-5.0)]$. At least to have attended a formal, education despite grade level hada significant association with the use of ITNs [OR $=1.8$, $95 \% \mathrm{CI}=(1.39-2.5)]$. Similarly, health education had significantly affected correctutilization ofITNs $[\mathrm{OR}=2.5$, $95 \% \mathrm{CI}=(1.2,2.7)]$.There was no observed significant association between use of mass media andcorrect use of bed nets $[\mathrm{OR}=1.3,95 \% \mathrm{CI}=(0.5,3.7)]$.

The respondent's educational level wassignificantly associated with treatment seeking habit $[\mathrm{OR}=5.1,95 \% \mathrm{CI}=$ $(2.9-6.2)]$. Subjects who completed at least $9^{\text {th }}$ grade were five times more likely to seek treatment earlycompared to those whodo not have attended formal education.Subjects in urban setting were more likely to seek early therapy $[\mathrm{OR}=2.1,95 \% \mathrm{CI}=(1.2,3.6)]$.
It was also shown that those who received health education were more likely to seek treatment earlier than those who didnot $[\mathrm{OR}=2.3,95 \% \mathrm{CI}=(1.3,4.1)]$.Out of 135 respondents who owe and use any of mass media like (radio, television ormagazines), 99(73.3\%) reported that they would seek treatment early. Fifty-four percentof thosewho did not use mass media had sought treatment within 24 hours of the onset of malariasymptoms. Utilization of mass media was significantly associated with early treatment seekingbehavior $[\mathrm{OR}=1.9,95 \% \mathrm{CI}=(1.2,3.4)]$.It is shown that $160(65 \%)$ of the respondents who lived farther than 60 minutes of walkingdistance to health facilitiesand $76(54.3 \%)$ of those who lived close to any of the health facilitiesreported having sought treatment within 24 hours of the onset of malaria symptoms.There was no statistically significant association between living farther than 60 minutes ofwalking distance to health institution and delay in treatment seeking $[\mathrm{OR}=1.3$, $95 \% \mathrm{CI}=(1.1,2.0)]$.

Table 4. Predictors of malaria knowledge and practice in PaweWoreda, Pawe, Ethiopia,November-December, 2010.Logistic regression analysis showing the adjusted OR for allvariables and their $95 \%$ confidence intervals $(95 \% \mathrm{CI})$.

\begin{tabular}{|c|c|c|c|c|c|c|}
\hline \multirow[b]{2}{*}{ Variables } & \multicolumn{2}{|c|}{ Malaria knowledge score(a) } & \multicolumn{2}{|c|}{ Correct use of ITNs } & \multicolumn{2}{|c|}{ Early treatment seeking } \\
\hline & $\begin{array}{l}\text { Crude } \\
\text { OR(95\%CI) }\end{array}$ & $\begin{array}{l}\text { Adjusted } \\
\text { OR(95\%CI) }\end{array}$ & $\begin{array}{l}\text { Crude } \\
\text { OR(95\%CI) } \\
\end{array}$ & $\begin{array}{l}\text { Adjusted } \\
\text { OR(95\%CI) }\end{array}$ & $\begin{array}{l}\text { Crude } \\
\text { OR(95\%CI) }\end{array}$ & $\begin{array}{l}\text { Adjusted } \\
\text { OR(95\%CI) }\end{array}$ \\
\hline Age (years) & & & & & NA & NA \\
\hline $18-24$ & 1 & & 1 & & & \\
\hline $25-34$ & $0.82(0.2-3)$ & & $0.6(0.07-4.3)$ & & & \\
\hline $35-44$ & $0.71(1.2-2.7)$ & & $1.1(0.3-3.5)$ & & & \\
\hline $45-54$ & $0.4(0.1-1.4)$ & & $0.8(0.2-3.4)$ & & & \\
\hline$>55$ & $0.5(1.1-2.2)$ & & $0.3(0.06-2.0)$ & & & \\
\hline \multicolumn{7}{|l|}{ Level of education } \\
\hline No formal education & 1 & 1 & 1 & 1 & 1 & 1 \\
\hline $1-4^{\text {th }}$ grade & $1.6(1.2-4.1)$ & $1.7(0.7-1.8)$ & $0.5(0.08-2.7)$ & $0.2(0.1-1.7)$ & $0.5(0.2-1.7)$ & $0.5(0.1-2.5)$ \\
\hline $5-8^{\text {th }}$ grade & $2(0.6-2.2)$ & $2.9(1.1-4.6)$ & $1.7(0.05-2)$ & $1.8(1.39-2.5)$ & $1.4(1.1-3.4)$ & $2.2(1.7-4.1)$ \\
\hline $9^{\text {th }}$ and above & $6.2(1.9-10.2)$ & $4.9(1.4-8.0)$ & $3.1(0.04-2.8)$ & $2.1(1.09-4.3)$ & $1.5(1-6)$ & $5.1(2.9-6.2)$ \\
\hline \multicolumn{7}{|l|}{ Residence } \\
\hline Urban & $0.7(0.4-1.2)$ & $1.5(1.2-4.5)$ & $1.1(0.4-3.2)$ & $1.2(0.4-3.7)$ & $2.2(1.4-3.4)$ & $2.1(1.2-3.6)$ \\
\hline Rural & 1 & 1 & 1 & 1 & 1 & 1 \\
\hline \multicolumn{7}{|l|}{ Source of income } \\
\hline Variable & 1 & 1 & NA & NA & 1 & 1 \\
\hline Constant & $1.3(0.5-2.2)$ & $1.8(1.08-3.8)$ & & & $1(0.5-1.9)$ & $1.7(1.1-2.2)$ \\
\hline \multicolumn{7}{|l|}{ Health education } \\
\hline Yes & 1 & 1 & 1 & 1 & 1 & 1 \\
\hline No & $0.6(0.3-1.1)$ & $0.2(1.9-3.2)$ & $0.5(0.1-1.8)$ & $2.5(1.2-1.7)$ & $2(1.09-3.30)$ & $2.3(1.3-4.1)$ \\
\hline \multicolumn{7}{|l|}{ Acces to mass media } \\
\hline Yes & $1.5(0.8-2.6)$ & $1.7(1.3-4.2)$ & $1.4(0.4-3.2)$ & $1.3(0.5-3.7)$ & $2.3(1.5-3.6)$ & $1.9(1.2-3.4)$ \\
\hline No & 1 & 1 & 1 & 1 & 1 & 1 \\
\hline \multicolumn{7}{|l|}{ Distance from Hf } \\
\hline$<60$ minutes & NA & NA & $0.9(0.3-2.7)$ & $1(0.3-2.7)$ & $1.6(1-2.4)$ & $1.3(1.1-2.0)$ \\
\hline$>60$ minutes travel & & & 1 & 1 & 1 & 1 \\
\hline
\end{tabular}

$H f:$ Health Facility, (a) = high knowledge score

\section{Discussion}

In this study most subjects $(98.5 \%)$ were aware of at least one symptom of malariaand $71.5 \%$ mentioned at least three symptoms. However, only $45.3 \%$ of subjectsassociated malaria withmosquito bite as a cause. The level of knowledge about malaria transmission was low when compared to the findings in previous studies carried out in other regions within Ethiopia [6, 10]. Our study findings about the mode of malaria transmission was also lower than those reported from studies carried out in other African countries[11, 12, 13], and in countries like India and Mexico [14, 15]. On the other hand,while $58 \%$ of subjects reported that malaria would cause death unless treated, $97 \%$ believed that it could be 
prevented. Similar results were found in other studies $[16,17$, and 18$]$. This could be due to similarity in study setting and the role of health information and communication equally reached.The level of awareness regarding malaria signs and symptoms, as well as the perceived seriousness of the disease reported in this study were higher than the findings in holo-endemic areas of Western Kenya [19]. This could be probably be due to the fact that people in malaria endemic areas are more likely to be more knowledgeable about disease than those in malaria free or low endemic areas.Only a small proportion $(31.8 \%)$ of the subjects in this study stated that mosquitoes would restindoors and $78 \%$ stated that mosquitoes bite during night. This was lower than astudy done in Asossa Western Ethiopia. [16]. A substantial proportion of the study subjects $(89.7 \%)$ mentioned that they would prefer sleeping under bed net to prevent malaria.This was higher than the results reported in different studies [19, 22,23, 17, and 18]. This attitude may be due toincreased health promotion activities and campaigns by the government and time reference of the study. Regarding the pattern of bed net utilization, 281(69.9\%) of the respondents reported correct use ofITNs (all year round and all family members slept under net). This was higher than the resultreported in Tigray [18]. This may be due to difference in study setting, the local community socio-cultural factors and time reference of the study.In the present study $42.4 \%$ of the study participants seek treatment after 24 hours delay of theonset of malaria symptoms. This was higher than that reported in Swaziland [23] and lower than the result reported in Bangladesh and Sudan[24, 25]. Access to health facility, availability of anti-malaria drugs, socio-cultural beliefs and exposure tohealth information might explain the observed variations.

Determinants of malaria knowledge, attitude and practice:In this study, being 5th grade and above was significantly associated with high malaria knowledge score. This finding was consistentwith the study done in Assosa and Tigray regions of Ethiopia [17, 18]. This similarity may be explained by the fact that educatedcommunities had better access to multiple source of information such as magazines, radio, and television and from their school education.Our currentstudy showed that urban residents were more likely to report higher comprehensiveknowledge of malaria than the rural people. This could be due to the fact that largeproportions of literate participants in the study were from the urban settings. Respondents who had not reported attendance of health education were less likely to report a high scoreof malaria knowledge. This may imply that health education had played a role by increasing thepeople's comprehensive knowledge in both settings.

Those who own and use radio and or television were more likely to mention a high malariaknowledge score than those who do not have access to mass media. Similar results werereported in other studies [18]. This could be due to similarity in the study design and socioeconomic status of the study participants in both settings and may imply that use of mass media and promotion of health education supplement the sources of malaria information.

Having attended any formal education and health education wereassociated with correct use of ITNs. This was in line with a study done in other settings[17, 18].However living close(less than 60 minutes walking) to any health facilitywas not associated with correct use of bed nets. This contrasts with the findings reportedin Tigray[18]. In ourstudy, the use of mass media like radio was not associated with correct use of ITNs. This finding was in contrast with a study done in Tigray region of Ethiopia [18], whichmay be explained by difference in study setting and frequency of radio use.

Regarding treatment seeking behavior,thosehavingformal education, andconstant monthly income, were significantly associated with early treatmentseeking habit within 24 hours of the onset of malaria symptoms. This finding wasconsistent with the study done in other study $[18,26]$.

In this study we have shown that those who did not receive health education and live furtherthan 60 minutes of walking to any of the health institution were less likely seek therapy early than those who live close to health facilities. A similarresult has been reported in other studies [18, 26]. This may be due to similarity in socioeconomic status of study participants, study design and accessibility of health facilities in both settings.

\section{Conclusions and Recommendations}

Despite a high knowledge and attitude scores towards malaria, there were still misconceptions about the causes of the disease and curative means.Sleeping under bed net was the single most common malaria prevention measure reported. But a gap in appropriate utilization of bed net identified.A significant proportion of the study participants would not seek treatment early.To not have a formal education was strongly associated with low knowledge score. To not have attended both general education and health education were significantly associated with low Knowledge score, inappropriate use of ITN, and delay intreatment. To be rural resident and not to own radio/television were both associated with low knowledge score and delay in treatment. Lack of health education and to live farther than 60 minutes distance walking from health facility were factors associated with a delay in treatment seeking. Hence, we recommend a comprehensive health education and promotion of community education to be given. Health facility coverage to remote areas should also be emphasized.Responsible bodies including Community Health Workers/CHWs are also urged toensurethat all individual in a household use ITNs correctly, adapt integrated vector control approach and seek treatment early as these are crucial to realize malaria elimination program by 2020 in selected endemic areas of Ethiopia.

\section{Authors' Contributions}

HBBeyene wrote the proposal, participated in data collection, analyzed the data and drafted the paper. NFTeleleand 
AHMekuriatake part in proposal development, participated in data analysis and revised subsequent drafts of the paper. All authors read and approved the final manuscript.

\section{References}

[1] Stephen H. Gillespie.(2001). Principles and practice of clinical parasitology, second edition. John Wiley and sons Ltd. P(573).

[2] Kayser, Medical Microbiology, part V (Parasitology), 2nd edition, 2005. (p 520).

[3] USAID/CDC. (2010). Malaria operational plan (MOP) Ethiopia, FY 2010. Available at: http://ethiopia_mop-fy10.pdf . Accessed on 20, August

[4] Deressa W. Malaria prevention and control in Ethiopia. National malaria contol program,ministry of health, Addis Ababa, Ethiopia;2010

[5] Malaria Operational Plan. President'smalaria initiative. USAID, Addis Ababa, Ethiopia 2013

[6] Jimma D, Tesfaye G, Deressa W, Woyessa A, KebedeDeressa W, Ali A, Enquoselassie F. Knowledge, Attitude and Practice about Malaria, the Mosquito and Antimalarial Drugs in a Rural Community. Ethiopian Journal of Health Development, 2003; 17(2):99-104.

[7] Claudia B., Aboubakary S., Evelyn W., et al. (2007). Malaria in rural Burkina Faso: local illness concepts, patterns of traditional treatment and influence on health-seeking behavior.Malaria Journal 2007, 6:106

[8] Aynalem A. Malaria in Ethiopia. President's Malaria Initiative MalariaOperational Plan (MOP). Ministry of health, Addis Ababa, Ethiopia;(2008).

[9] Forney J., Majill A., Heppaner D., et al (2001). Malaria rapid diagnostic devices and performance characterstics of ParaSigh $t F$ device determined in multisite field study. Journal of ClinicalMicrobiologyl; 39(8); 2884-2890.

[10] Jimma D, Tesfaye G, Deressa W, Woyessa A, Kebede D, Alameraw D. Baseline survey for the implementation of Insecticide -treated mosquito nets in malaria control in Ethiopia. Ethiopian Journal of Health Development, 2005; 19(1):16-23.

[11] Adongo PB, Kirkwood B, Kendall C. How localcommunity knowledge about malaria affectsinsecticide treated net use in northern Ghana.Tropical Medicine and International Health, 2005;10(4):366-378.

[12] Tyagi P, Roy A, Malhotra MS. Knowledge, awareness and practices towards malaria in communities of rural, semi-rural and bordering areas of east Delhi, India. Journal of Vector Borne Diseases; 2005; 42:30-35.

[13] Adera TD. Beliefs and traditional treatment of malaria in Kishe settlement area, South West Ethiopia. Ethiopian Medical Journal, 2003; 41(1):25-34.

[14] Roderiguez $\mathrm{AD}$ et al. Knowledge and belief aboutmalaria transmission and practices for vector controlin southern Mexico. SaludPublica de Mexico, 2003;45(2).

[15] Binka FN, Indome F, Smith T. Impact of spatialdistribution of
Permethrin-Impregnated bed nets onChild Mortality in Rural Northern Ghana. American Journal of Tropical Medicine and Hygiene, 1998; 59(1):80-85.

[16] Safari M., Fabian M., Joseph R., et al. (2010). Knowledge, attitudes and practices about malaria among communities: Comparing epidemic and non-epidemic prone communities of Muleba district, North-western Tanzania. BMC Public Health $10: 395$

[17] Legesse Y., Tegegn A., Belachew T., Tushune K. (2007). Knowledge, attitude and practice about malaria transmission and its preventive measures among households in Urban Areas of Assosa Zone, Western Ethiopia. Ethiopian Journal of Health Development21(2): 157-165.

[18] Paulander J., Olsson H., Lemma H., Getachew A., San Sebastian M. (2009). Knowledge, attitudes and practice about malaria in rural Tigray, Ethiopia. Global Health Action. 10.3402/gha.v2i0.1839.

[19] Ongore, D., Kamunvi, F., Knight, R. and Minawa, A. (1989) A study of knowledge, attitudes and practices (KAP) of a rural community on malaria and the mosquito vector. East African MedicalJournal.; 66(2):79-89.

[20] Karunamoorthia K., Bekelea M. (2009). Prevalence of malaria from peripheral blood smears examination: A 1-year retrospective study from the Serbo Health Center KersaWoreda, Ethiopia. Journal of Infection and Public Health. 2: 171-176.

[21] Sultana A., Mohammad A. (2001). Malaria knowledge, attitude \& practice; in a semi urban population of Rawalpindi. Professional Medical Journal Rawalpindi Medical College, Rawalpindi .8(4): 433-8

[22] Oyewole and Ibidapo. (2007). Attitudes to malaria, prevention, treatment and management strategies associated with the prevalence of malaria in a Nigerian urban center. African Journal of Biotechnology. 6 (21): 2424 -2427

[23] Khumbulani W., Musawenkosi L., Mabasoet al (2009). Community knowledge, attitudes and practices (KAP) on malaria in Swaziland: A country earmarked for malaria elimination. Malaria Journal 8:29

[24] Syed M., Rashidul H., Ubydul H., Awlad H. (2009). Knowledge on the transmission, prevention and treatment of malaria between two endemic populations of Bangladesh and their health-seeking behavior Licensee BioMed Central Ltd..Malaria Journal 8:173.

[25] Salwa.M., El-Gayoum¹., Hayder A., et al.(2009). Knowledge, practices and perceptions which affect acquiring malaria in man-made malarious area in Khartoum State, Sudan.Sudanese Journal of Public Health. 4(1): 15-17

[26] Ashis D., Sundari T., Ravindran A. (2010). Factors affecting treatment-seekingfor febrile illness in a malaria endemic block in Boudh district, Orissa, India: policy implications for malaria control. Malaria Journal, 9:377

[27] Runsewe-Abiodun, Iyabo T1 and RunseweOlugbenga. Attitude and practice of pregnant women to use of insecticide treated nets in South-West Nigeria. African Journal of Pregnancy and Childbirth 2013: 1(1) pp. 001-009, Available online at: www.internationalscholarsjournals.org (C) International Scholars Journals 